Dhaka Univ. J. Biol. Sci. 20(1): 65-70, 2011 (January)

\title{
EFFECTS OF IRRADIANCE AND PENETRATION RESISTANCE ON ROOT AND SHOOT GROWTH OF RICE
}

\author{
A.H.M.Z. Ali* \\ Plant E Soil Science Department, University of Aberdeen, Aberdeen AB24 3UU, U.K. \\ Key words: Irradiance, Penetration resistance, Growth, Rice
}

\begin{abstract}
Plants of BR-29 rice were grown at low (0.05 MPa) and high (0.9 MPa) penetration resistances under low $\left(187 \mu \mathrm{mol} / \mathrm{sec} / \mathrm{m}^{2}\right)$ and high $\left(375 \mu \mathrm{mol} / \mathrm{sec} / \mathrm{m}^{2}\right)$ irradiances for three and nine days. There was no significant effect of irradiance $(p>0.05)$ on seminal root axis lengths of rice at three days after transplanting. At nine days after transplanting, seminal root axis lengths were significantly greater in high than low irradiances $(\mathrm{p}<0.05)$, but only in low penetration resistance. Significant effect $(\mathrm{p}<0.05)$ was also found on number of laterals in both low and high penetration resistances. In case of shoot lengths no significant differences ( $P$ $>0.05$ ) were found at three or nine days after transplanting between low and high irradiances. But increase in leaf length with time was higher at low irradiance (up to 120 hours) than at high irradiance (up to 96 hours). However, in the phytotron, plants were getting irradiance at a constant rate for the total day length (12 hours) with little mutual leaf shading. It was assumed that these conditions would be likely to give a rate of photosynthesis close to the maximum. Therefore, it may be concluded from this experiment that irradiance can have more prominent effect on root than shoot at different penetration resistances in soil.
\end{abstract}

\section{Introduction}

Light saturation occurs in plants with typical value of irradiance.(1) Irradiance has a significant effect on growth and yield of rice. Penetration resistance is the physical resistance that a soil offers to the elongation of roots.(2) Deeper the shade, the less water limits growth, so the less impact of penetration resistance. At higher penetration resistance, soil suffers from availability of water and oxygen supply. Soil dryness varies differently across irradiance regime in different systems. ${ }^{(3)}$ One fundamental question is that whether this effect is higher or lower at low (deep shade) or high (without shade) irradiances. Irradiance affects the vegetative, reproductive and ripening stages of rice.(4) In field conditions, solar irradiance increases from sunrise and reaches its maximum level at mid-day and then decreases. Shade reduces leaf and air temperatures, vapour-pressure deficit, and the oxidative stresses that can aggravate the impact of drought at higher irradiance. ${ }^{(5)}$

*Present address: Department of Soil, Water \& Environment, University of Dhaka, Dhaka-1000, Bangladesh 
A knowledge of seedling growth responses to combined effects of shade and drought, i.e., a given reduction in soil matric potential is important to explain relational position of species in higher plants.(6) As a result, it is important to know how the rice plant behaves at different irradiances in response to penetration resistances in soil in green house conditions. Therefore, this experiment was carried out to see the effects of irradiance on the root and shoot growth of rice in both low (unimpeded) and high penetration (impeded) resistances in soil.

\section{Materials and Methods}

Perspex cylinders were packed with soil uniformly mixed with nutrient solution following the packing styles developed for an unimpeded treatment with a penetration resistance (PR) of $0.05 \mathrm{MPa}$ and an impeded treatment with a PR of $0.9 \mathrm{MPa}$. Variation in mean penetration resistances within a cylinder in unimpeded $(\mathrm{PR}=0.05 \mathrm{MPa})$ and impeded $(\mathrm{PR}=0.9 \mathrm{MPa})$ treatments are shown in Fig. 1 .
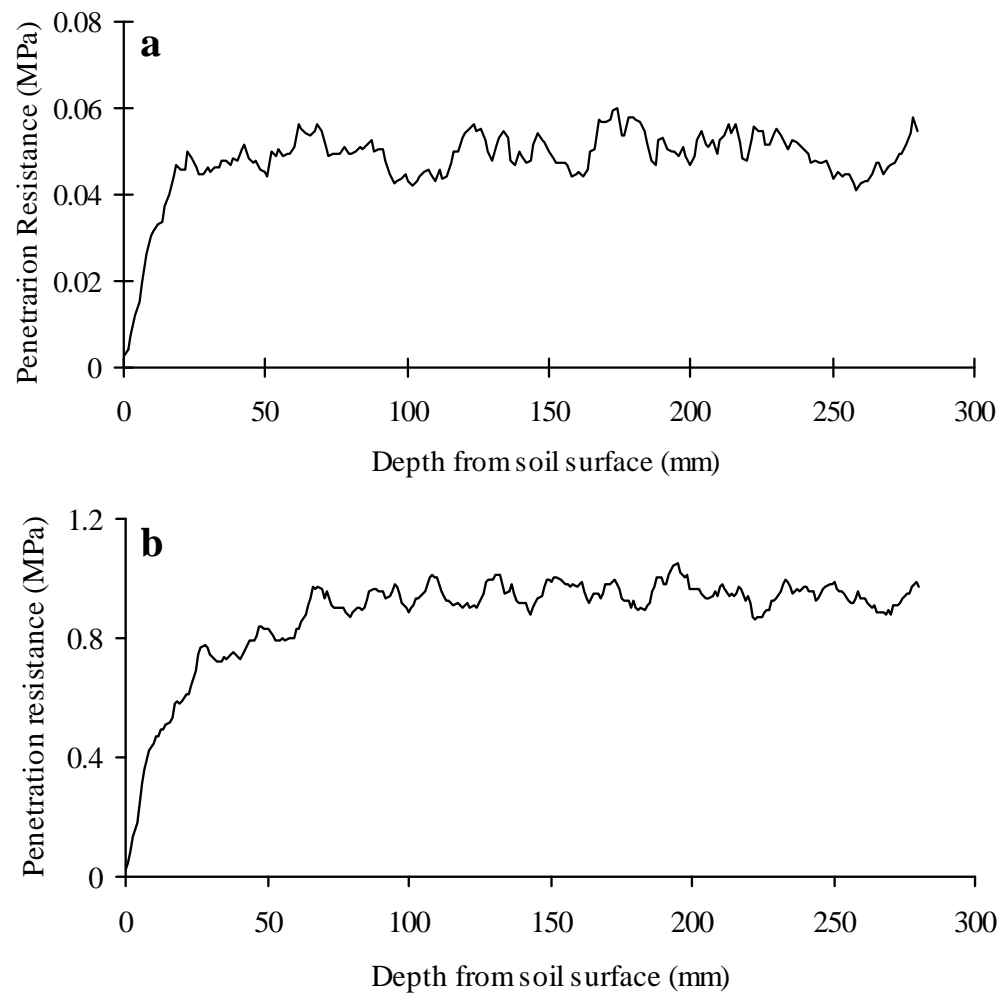

Fig. 1. Variation in mean penetration resistance (PR) with depth within a cylinder for (a) unimpeded treatment, low $\mathrm{PR}=0.05 \mathrm{MPa}$ and $(\mathrm{b})$ impeded treatment, high $\mathrm{PR}=0.9 \mathrm{MPa}$.

Seeds of BR-29 variety of rice were germinated on wet filter paper. Preliminary germination trials were carried out to determine germination rates under these 
conditions. Thus, the times when the seeds were placed on wet filter paper were chosen to ensure that each seed was at the same stage of germination when transferred to the packed growth cylinders.

Packed cylinders were placed in high light phytotron. Irradiance inside the phytotron varied from $\left(320-430 \mu \mathrm{mol} / \mathrm{m}^{2} / \mathrm{s}\right)$. The phytotron was separated into two parts by placing shade cloth over half of the phytotron. Average irradiance inside the phytotron without shade cloth was $375 \mu \mathrm{mol} / \mathrm{sec} / \mathrm{m}^{2}$ and under shade cloth was $187 \mu \mathrm{mol} / \mathrm{sec} / \mathrm{m}^{2}$. Average temperature inside the phytotron was about $27^{\circ} \mathrm{C}$.

At the time of harvesting, the growth cylinders were collected from the high light phytotron and submerged in a container full of water for one hour after removing the base of cylinders. When the soil became loose it fell freely down the cylinder as it was removed from the cylinder. The plants were then collected from the container placed in a Petri dish, and washed thoroughly with distilled water to remove soil or sand attached to the roots. The plants were temporarily kept in these Petri dishes full of water during mearuement of root and shoot parameters.

The length of the seminal root axis was measured using digital vernier callipers $( \pm$ $0.01 \mathrm{~mm}$ ). The number of first order laterals were counted under a large-field illuminated bench magnifier keeping the root system in a Petri dish.

Shoot length (longest leaf) was measured to $\pm 0.01 \mathrm{~mm}$ using digital vernier callipers. Increase in leaf lengths were also measured at 24 hour intervals in both unimpeded and impeded treatments.

Statistical analysis was made using Minitab Statistical Software, release 10 Xtra.

\section{Results and Discussion}

Effect of irradiance on seminal root axis lengths of BR-29 variety of rice at low (0.05 $\mathrm{MPa})$ and high $(0.9 \mathrm{MPa})$ penetration resistances (PRs) at two different growth periods are shown in Fig. 2. There was no significant $(p>0.05)$ effect of irradiance on seminal root axis lengths of rice at three days after transplanting. At 9 days after transplanting, seminal axis lengths were significantly $(p<0.05)$ greater in light than in shade environment, but only in the low penetration resistance (Fig. 2b). Significant effects of irradiances were also found on number of laterals in both low and high penetration resistances (Fig. 3b). Reinhard et al. ${ }^{(7)}$ also found that at low irradiance $\left(190 \mu \mathrm{mol} / \mathrm{s} / \mathrm{m}^{2}\right)$, root growth of pea (Pisum sativum L.) was reduced more than shoot growth.

Effect of irradiance on shoot lengths of BR-29 variety of rice at low (0.05 MPa) and high $(0.9 \mathrm{MPa})$ penetration resistances (PRs) at two different growth periods are shown in Fig. 4. There were no significant $(p>0.05)$ differences in the shoot lengths of rice at three or nine days after transplanting between high and low irradiances. Under low irradiance (shade environment), increase in the length of leaf with time for both low (unimpeded) and high (impeded) penetration resistances were observed from 48 to 120 
hours, but in case of high irradiance (light environment), this increase was up to 96 hours (Fig. 5). According to Marschner(8), limitation of photosynthesis by low irradiance inhibits root growth more than shoot growth.
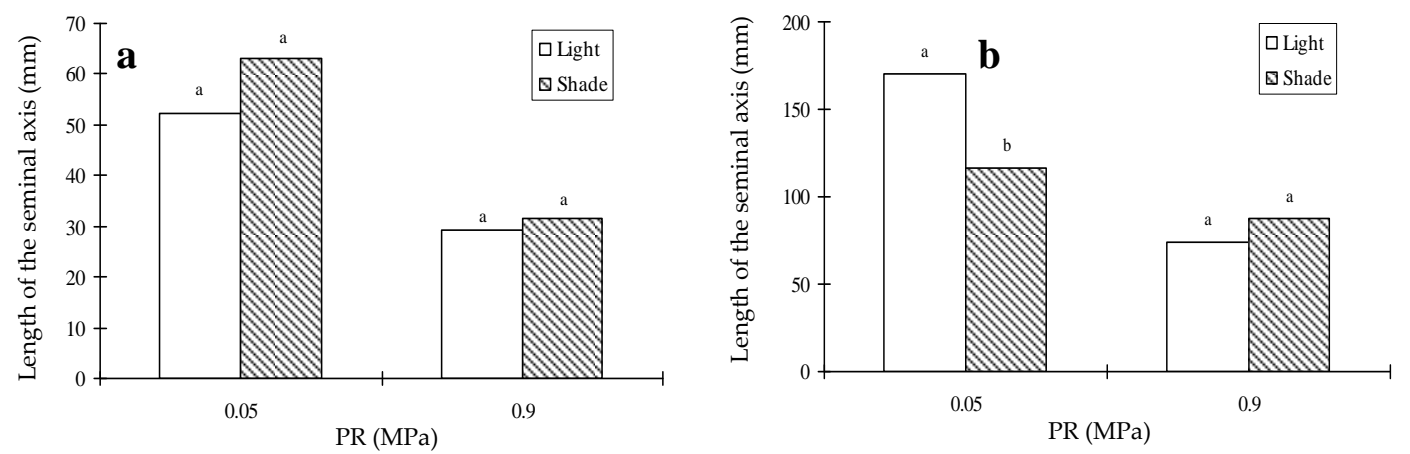

Fig. 2. Effect of irradiance on seminal root axis lengths of BR-29 variety of rice at low (0.05 MPa) and high (0.9 $\mathrm{MPa}$ ) penetration resistances (PRs) at two different growth periods: (a) three days after transplanting and (b) nine days after transplanting. For each PR treatment, seminal axis lengths that do not differ significantly $(\mathrm{p}<$ $0.05)$ share the same letter.
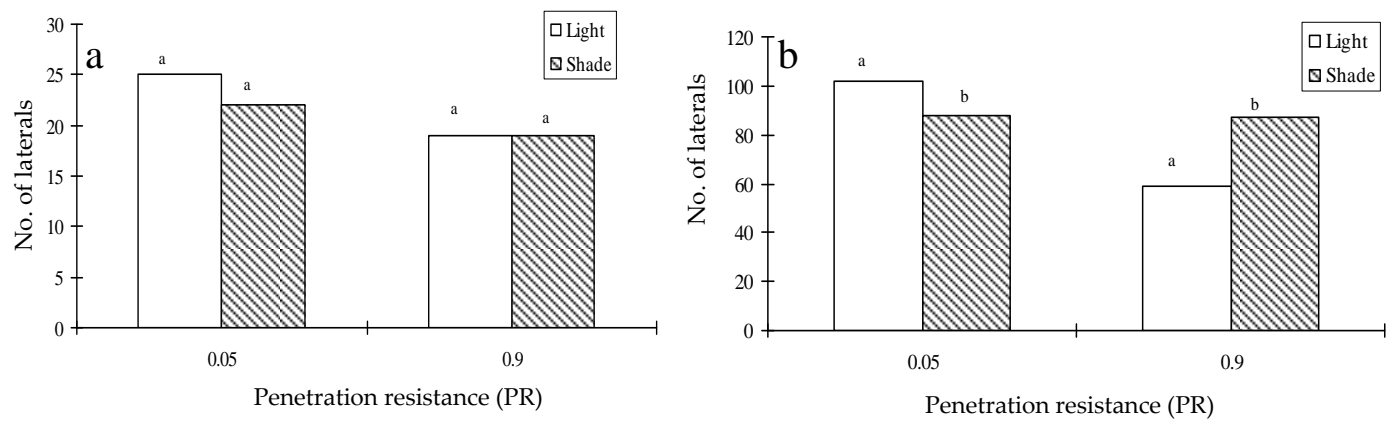

Fig. 3. Effect of irradiance on number of laterals of BR-29 variety of rice at low (0.05 MPa) and high (0.9 MPa) penetration resistances (PRs) in two different growth periods: (a) three days after transplanting and (b) nine days after transplanting. For each PR treatment, number of laterals that do not differ significantly $(p<0.05)$ share the same letter.
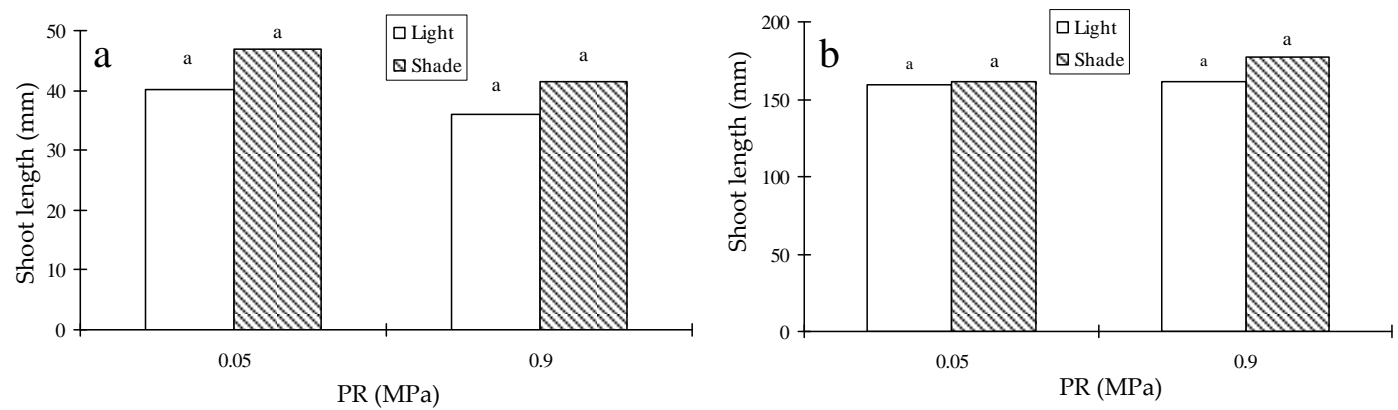

Fig. 4. Effect of irradiance on shoot lengths of BR-29 variety of rice at low (0.05 MPa) and high (0.9 MPa) penetration resistances (PRs) in two different growth periods: (a) three days after transplanting and (b) nine days after transplanting. For each PR treatment, shoot lengths that do not differ significantly $(\mathrm{p}<0.05)$ share the same letter. 
Although a high light phytotron (320 - $430 \mu \mathrm{mol} / \mathrm{m}^{2} / \mathrm{s}$ ) was chosen for this experiment, irradiance in the phytotron was still low compared to the maximum that occurs in field conditions. Irradiance in temperate latitudes at mid-day in summer is about $1,800 \mu \mathrm{mol} / \mathrm{m}^{2} / \mathrm{s}^{(9)}$ and in the tropics with full sun (noon, cloudless), $1840-2400$ $\mu \mathrm{mol} / \mathrm{m}^{2} / \mathrm{s}^{(10)}$. Photosynthesis in plants at high irradiance also depends upon the supply of $\mathrm{CO}_{2}$ and consequently, light saturation occurs in rice ( $\mathrm{C}_{3}$ plants) at an irradiance of typically $400-600 \mu \mathrm{mol} / \mathrm{m}^{2} / \mathrm{s} .^{(1)}$ In field conditions, solar irradiance increases from sunrise

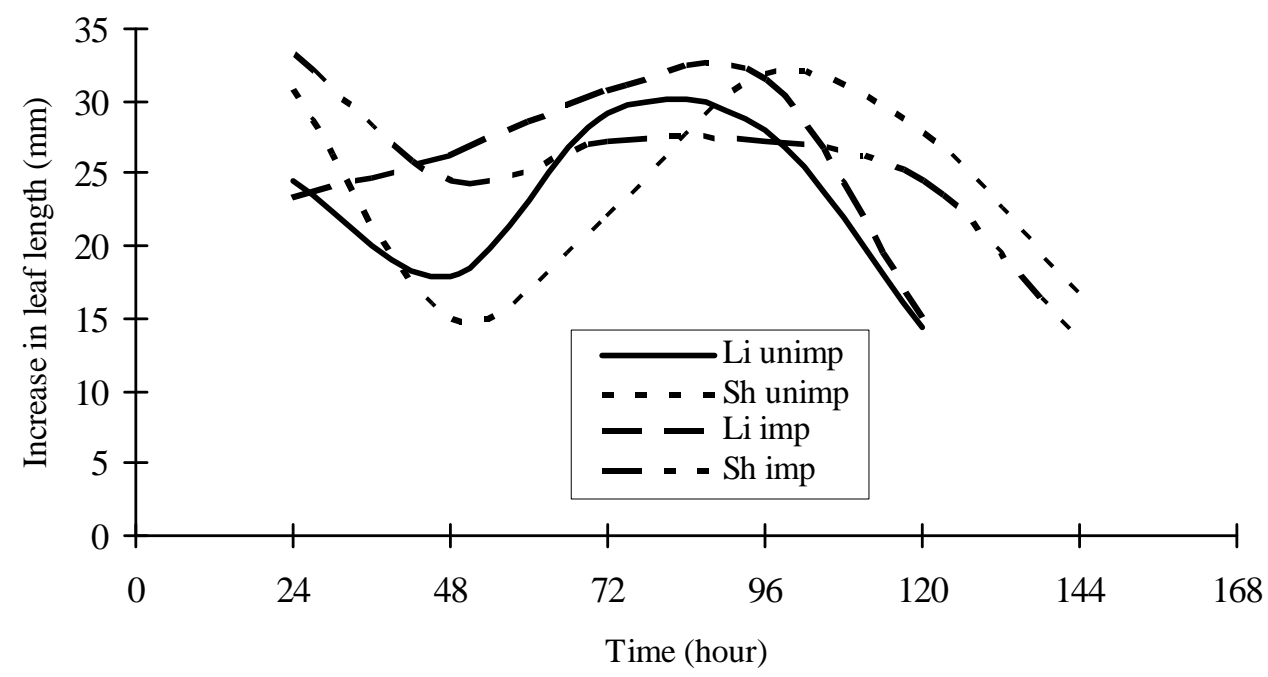

Fig. 5. Increase in leaf length (longest leaf) with time in unimpeded, low $\mathrm{PR}=0.05 \mathrm{MPa}$ and impeded, high $\mathrm{PR}=0.9 \mathrm{MPa}$ treatments under low (Sh) and high (Li) irradiances.

and reaches its maximum level at mid-day and then decreases. However, in the phytotron, plants were getting irradiance at a constant rate for the total day length (12 hours) with little mutual leaf shading. It was assumed that these conditions would be likely to give a rate of photosynthesis close to the maximum. Consequently, it was felt that these conditions were as close to tropical field conditions which could be reasonably achieved in the laboratory under constant irradiance. Therefore, it may be concluded from this experiment that effects of irradiance is more pronounced on root than shoot growth at different penetration resistances in soil.

\section{Acknowledgements}

The author is highly grateful to his Ph.D. supervior Dr. C.E. Mullins. He is also grateful to Mr. Inverarity, Invararity Farms, Dundee for supply of soil. 


\section{References}

1. Salisbury FB and CW Ross 1992. Plant Physiology (4th edition). Wadsworth Publishing Company, USA.

2. Vepraskas MJ 1994. Plant response mechanisms to soil compaction. In: Plant- Environment Interactions (Wilkinson RE Ed.), pp. 263-287. Marcel Dekker Inc., New York.

3. Abrams MD 1986. Physiological plasticity in water relations and leaf structure of understory versus open-grown Cercis canadensis in northeastern Kansas. Can. J. For. Res. 16: 11701174.

4. Fageria NK, V Baligar and CA Jones 1991. Growth and mineral nutrition of field crops. Marcel Dekker, Inc. New York.

5. Valladares F and RW Pearcy 1997. Interactions between water stress, sun-shade acclimation, heat tolerance and photoinhibition in the sclerophyll Heteromeles arbutifolia. Plant Cell Environ. 20: 25-36.

6. Walters $\mathrm{MB}$ and PB Reich 1997. Growth of Acer saccharum seedlings in deeply shaded understories of northern Wisconsin: effects of nitrogen and water availability. Can J. For Res. 27: 237-247.

7. Reinhard S, P Martin and H Marschner 1992. Interactions in the tripartite symbiosis of pea (Pisum sativum L.), Golmus and Rhizobium under non-limiting phosphorus supply. J. Plant Physiology 141: 7-11.

8. Marschner H 1995. Mineral Nutrition of Higher Plants. 2nd edition. Academic Press Limited, UK.

9. Hart JW 1988. Topics in Plant Physiology. 1. Light and plant growth. pp. 27-29. Unwin Hyman Ltd., London, UK.

10. Ridge I 1991. Plant Physiology: Biology: Form and Function. Hodder \& Stoughton Ltd., Kent, UK. 